\title{
Patients with Rheumatoid Arthritis Identified as Potentially Suitable for Biosimilar Infliximabin Europe
}

\author{
Siva Narayanan ${ }^{1}$, Yao Lu², Richard Hutchings ${ }^{3}$, Amanda Baskett ${ }^{4}$, Sam Mentzer $^{5}$ \\ ${ }^{1}$ Ipsos Healthcare, Washington, DC, USA

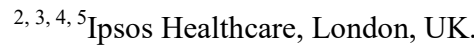 \\ Address for correspondence: \\ Siva Narayanan, MS MHS \\ SVP and Global Head, Global Evidence, Value and Access \\ Ipsos Healthcare, 2020 K Street, Washington, DC, 20006, USA, Phone: 301-605-3663 \\ Email: siva_narayanan@verizon.net
}

\begin{abstract}
Assessing physician perception of patients with rheumatoid arthritis (RA) they consider as Infliximab-biosimilar-suitable may provide insights into eventual biosimilar adoption in clinical practice settings in Europe. Medical charts of 1204 patients with rheumatoid arthritis (RA) from UK/France/Germany/Italy/Spain were abstracted; 425 were identified by physicians as biosimilarinfliximab-suitable; of these, 55\% were identified as candidates for being prescribing biosimilar-infliximab. For biosimilar-infliximabsuitable Yes/No groups, time since diagnosis: 67.1/85.3mo; percentage with moderate/severe disease (per physician judgment): 46\%/40\%; ESR:23.4/21.2mm/h; CRP:12.6/8.1mg/dl;VAS(0-10scale):3.7/3.4; Swollen Joint Count:2.6/1.9 and Tender Joint Count:4.4/3.1. RA patients considered infliximab-biosimilar not-suitable (per clinical judgment) had been in care for relatively longer period, had relatively lower disease severity and were less involved in treatment decisions. Physicians were also not readily prepared to prescribe the biosimilar to all infliximab-biosimilar-suitable $R A$ patients. Drivers behind observed physician perception warrant scrutiny.
\end{abstract}

Keywords: Rheumatoid Arthritis, Biosimilar, Infliximab, Europe

\section{Introduction}

Rheumatoid Arthritis (RA) is a chronic autoimmune disease that results in systemic inflammation and primarily attacks synovial joints [1].The disease morbidity is accompanied by a significant economic burden, in terms of direct healthcare costs (such as inpatient and outpatient costs) and indirect costs (such as costs associated productivity impairments) $[2,3]$.Treatments for RA has evolved over time and now include NSAIDs, steroids, traditional disease-modifying antirheumatic drugs (DMARDs), and biological DMARDs [4]. The introduction of biologics revolutionized the treatment of RA; targeting specific components of the immune system allows efficient suppression of the pathologic inflammation cascade which causes joint destruction, thereby significantly alleviating patient disease burden [5].However, these biologics are expensive and their continued use over an extended period of time necessitate resource allocation at national level challenging to actively manage RA population and associated burden.

Follow-on versions of biologics, namely, "biosimilars", have been recently introduced into the market and these may provide a cost effective alternative to the originator drugs.Biosimilar-version of the tumor necrosis factor inhibitor (anti-TNF) drug Infliximab is the first biosimilar monoclonal antibody to be approved in the European Union. The current uptake of this drug is however slow and thenational and regional regulatory framework for biosimilars is still evolving [6]. This may make it challenging for physicians, patients, and payers to trust the safety and efficacy of a biosimilar, compared to the reference biologic therapy [7].In a survey of Rheumatologists in Europe, Narayanan \& Nag (2015) found $60 \%$ of physicians in Europe reporting that they would definitely or be highly likely to prescribe a biosimilar to an eligible RA patient, while they expressed concerns over the biosimilar product attributes [8].

Rheumatologists will play a critical role in the adoption and effective use of biosimilars, as they will need to weigh up when to use a biosimilar versus the originator drug and for which patient [6,8-10]. Assessing physician perception of patients they consider as biosimilar-suitable (among those who were recently on biologics) may provide insights into eventual biosimilar adoption in clinical practice settings as well as any physician educational needs to foster best practices.

\section{Materials and Methods}

The study was a multi-center retrospective medical chart review of RA patients, conducted among rheumatologists in the big-5 European countries (EU5), namely, the UK, France, Germany, Italy and Spain.Rheumatologists were sampled in each of the countries using online physician panels to attain a geographically representative sample in each region. The physician panels were originally constructed to include a diverse set of physicians (in terms of geography and practice settings) within the respective 


\section{International Journal of Science and Research (IJSR) \\ ISSN (Online): 2319-7064 \\ Index Copernicus Value (2013): 6.14 | Impact Factor (2015): 6.391}

countries and explicit consent had been obtained from the physicians to contact them at any juncture to solicit their interest in participating in research using online data collection platforms. Invitations to participate in survey research were sent to a random set of rheumatologists in the existing panels. The physicians represented both hospitalbased and private practices in each geography, and had to treat a minimum of 2 RA biologic patients per week and have 3-30 years of clinical practice experience.Each physician reported de-identified data on patients who were recently treated with a biologic as part of usual care. Up to 5 eligible patient charts were randomly selected by each physician from a sample of prospective patients visiting their respective center/practice during the study screening period in 2015 .

The study data collection form gathered the following data elements: patient diagnosis, treatment patterns/dynamics, RA disease characteristics and outcomes (patient symptomatology/disease severity), patient suitability for biosimilar-infliximab (per physician judgement), physician likelihood to prescribe biosimilar infliximab to suitable patients and physician rating of level of involvement of RA patients in treatment decisions. The most recent disease severity measures such as tender joint count, swollen joint count, Disease Activity Score 28 (DAS28), Visual Analog Scale (VAS: 0-10) of global disease severity, Health Assessment Questionnaire (HAQ) score, and laboratory measures such as erythrocyte sedimentation rate (ESR), Creactive protein (CRP), cyclic citrullinated peptide antibodies (anti-CCP) and Rheumatoid factor test results that were recorded in the RA patient charts were abstracted.

Only de-identified anonymous data was collected from patient charts. Patients who were considered as biosimilarinfliximab-suitable versus those who were not (per physician judgement), excluding those previously failed infliximab were included in the final study analyses.

\section{Results}

Physicians abstracted 1204 eligible RA patient charts excluding patients with previous infliximab failures. Of these, $425(35 \%)$ were identified as biosimilar-infliximab suitable per physician judgement. (Table 1)

Table 1: Patient biosimilar-infliximab suitability by country

\begin{tabular}{|c|c|c|c|c|c|c|}
\hline & EU5 $(\mathrm{n}=1204)$ & UK $(\mathrm{n}=239)$ & France $(\mathrm{n}=233)$ & Germany $(\mathrm{n}=229)$ & Italy $(\mathrm{n}=252)$ & Spain $(\mathrm{n}=251)$ \\
\hline Suitable*: \% of patients & 35 & 46 & 27 & 36 & 41 & 27 \\
\hline Not Suitable*: \% of patients & 65 & 54 & 73 & 64 & 59 & 73 \\
\hline
\end{tabular}

*per physician judgement.

Note: EU5: UK, France, Germany, Italy and Spain; UK: United Kingdom.

Both the biosimilar-infliximab suitable and not suitable groups consisted of $73 \%$ female (range: and mean ages were 50.2 years and 51.6 years, respectively. The biosimilarinfliximab suitable patients had been diagnosed with RA for a significantly shorter period than the non-suitable group (67.1 months versus 85.3 months).

Mean number of lines of biologic use was 1.2 for biosimilarinfliximab suitable patients versus 1.4 for the not-suitable group. Biosimilar-infliximab suitable patients were less likely to be on steroids and more likely to be on an analgesic than their not-suitable counterparts. (Figure 1)
Forty six percentage of the biosimilar-infliximab suitable patients were considered to have moderate/severe disease (per physician global assessment / clinical judgement) compared to $40 \%$ of the not suitable group. Mean tender joint counts and mean swollen joint counts were higher for biosimilar-infliximab suitable patients, whereas the other disease severity scores such as DAS28, VAS and HAQ scores were similar. Lab values, namely, ESR and CRP, were worse among patients identified as biosimilarinfliximab suitable compared to patients not-suitable, whereas, percentage of patients testing positive for Rheumatoid factor and anti-CCP were relatively lower among biosimilar-infliximab suitable patients. (Table 2) 


\section{International Journal of Science and Research (IJSR) \\ ISSN (Online): 2319-7064}

Index Copernicus Value (2013): 6.14 | Impact Factor (2015): 6.391

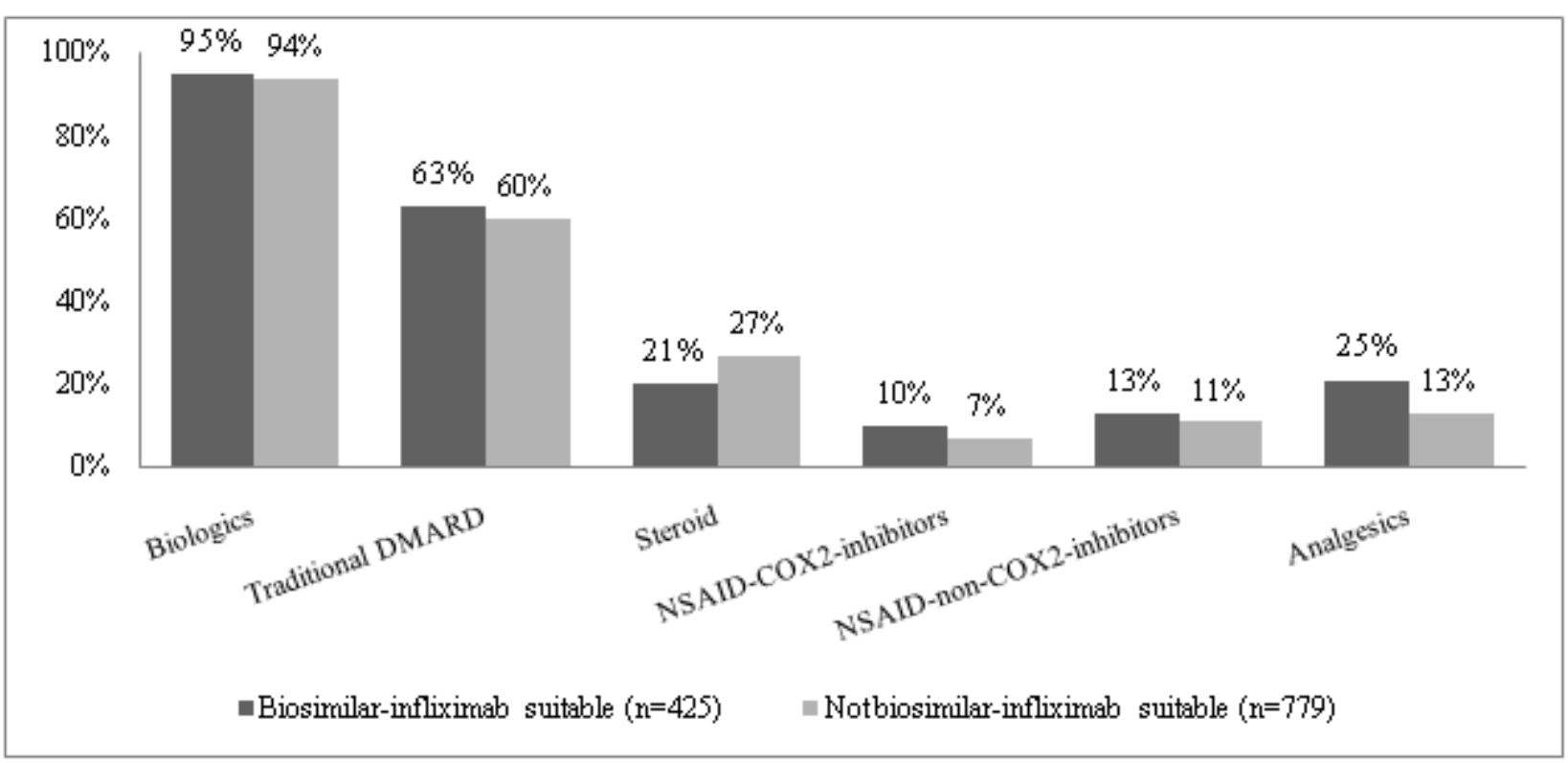

Figure 1: Current drug class usage

Note: DMARDS: Disease-modifying antirheumatic drugs; NSAID: Nonsteroidal anti-inflammatory drugs; COX2: Cyclooxygenase-2.

Table 2: Clinical characteristics: Latest disease severity measures

\begin{tabular}{|c|c|c|}
\hline Disease severity measures & $\begin{array}{c}\text { Biosimilar- } \\
\text { infliximab } \\
\text { suitable }\end{array}$ & $\begin{array}{c}\text { Not } \\
\text { biosimilar- } \\
\text { infliximab } \\
\text { suitable }\end{array}$ \\
\hline Tender joint count: mean (n) & $4.4(414)$ & $3.1(757)$ \\
\hline Swollen joint count: mean (n) & $2.6(414)$ & $1.9(757)$ \\
\hline DAS28 Score: mean (n) & $3.2(291)$ & $3.0(548)$ \\
\hline VAS (0-10 scale) Score: mean (n) & $3.7(319)$ & $3.4(657)$ \\
\hline HAQ Score: mean (n) & $1.0(119)$ & $1.0(197)$ \\
\hline Rheumatoid Factor: \% positive (n) & $84(423)$ & $86(762)$ \\
\hline Anti-CCP: \% positive (n) & $77(388)$ & $80(720)$ \\
\hline ESR values (mm/h): mean (n) & $23.4(383)$ & $21.2(733)$ \\
\hline CRP values (mg/dl): mean (n) & $12.6(403)$ & $8.1(757)$ \\
\hline
\end{tabular}

Note: DAS28: Disease Activity Score 28 (DAS28); VAS: Visual Analog Scale; HAQ: Health Assessment Questionnaire; ESR: Erythrocyte Sedimentation Rate; CRP: C-reactive Protein; anti-CCP: citrullinated peptide antibodies.

Overall, physicians across the countries reported that they involved their RA patients in treatment decisions (somewhat, very, very much) in $59 \%$ of cases, with a higher proportion reported within the biosimilar-infliximab suitable patients $(64 \%)$ in comparison to their not suitable counterparts $(56 \%)$.(Figure 2) This varied across the 5 countries.

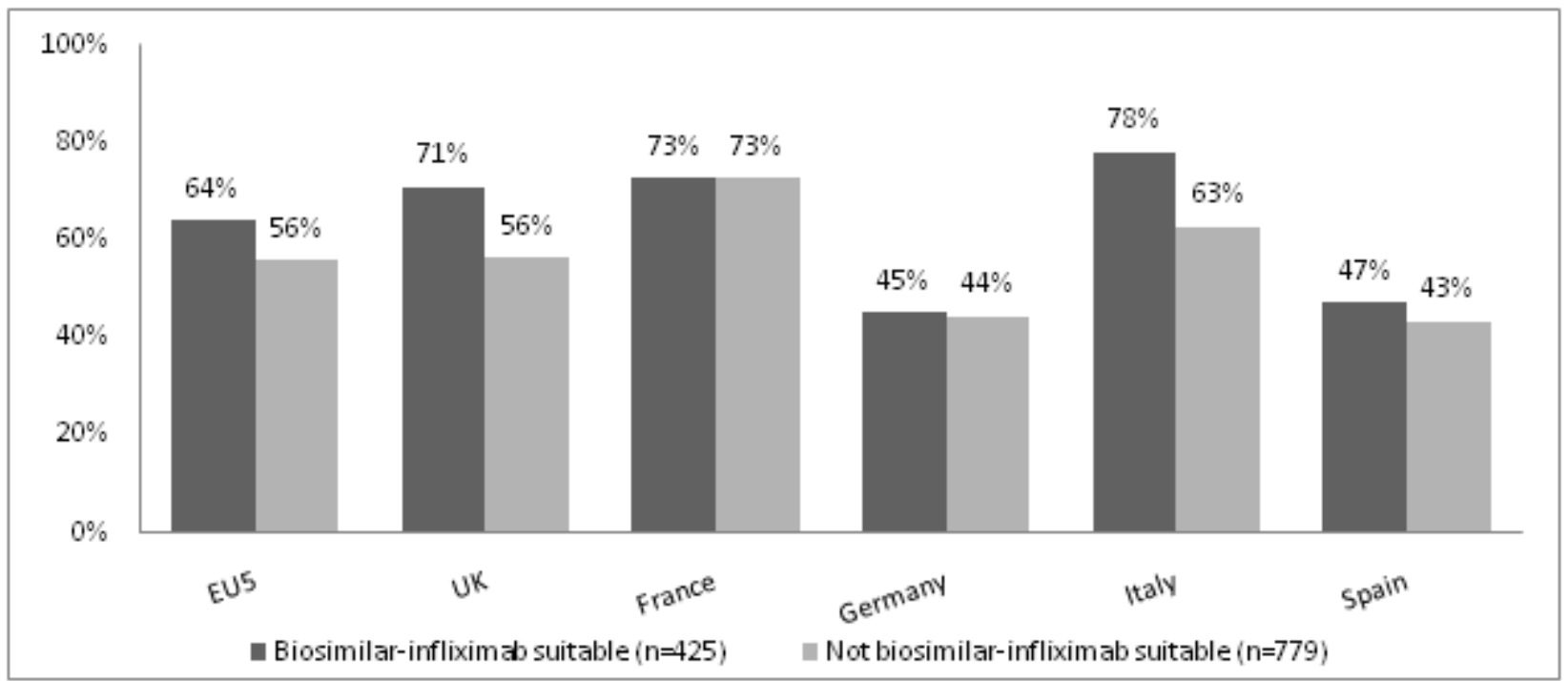

Figure 2: Physician rating of level of involvement of RA patients in treatment decisions

Note: EU5: UK, France, Germany, Italy and Spain; UK: United Kingdom.
Of those patients deemed biosimilar-infliximab suitable $(\mathrm{N}$ 425), physicians identified $55 \%$ of patients for whom they

\section{Volume 5 Issue 8, August 2016 www.ijsr.net}




\section{International Journal of Science and Research (IJSR) \\ ISSN (Online): 2319-7064}

Index Copernicus Value (2013): 6.14 | Impact Factor (2015): 6.391

would (somewhat, very or extremely likely) prescribe

biosimilar infliximab once it is available. (Figure 3)

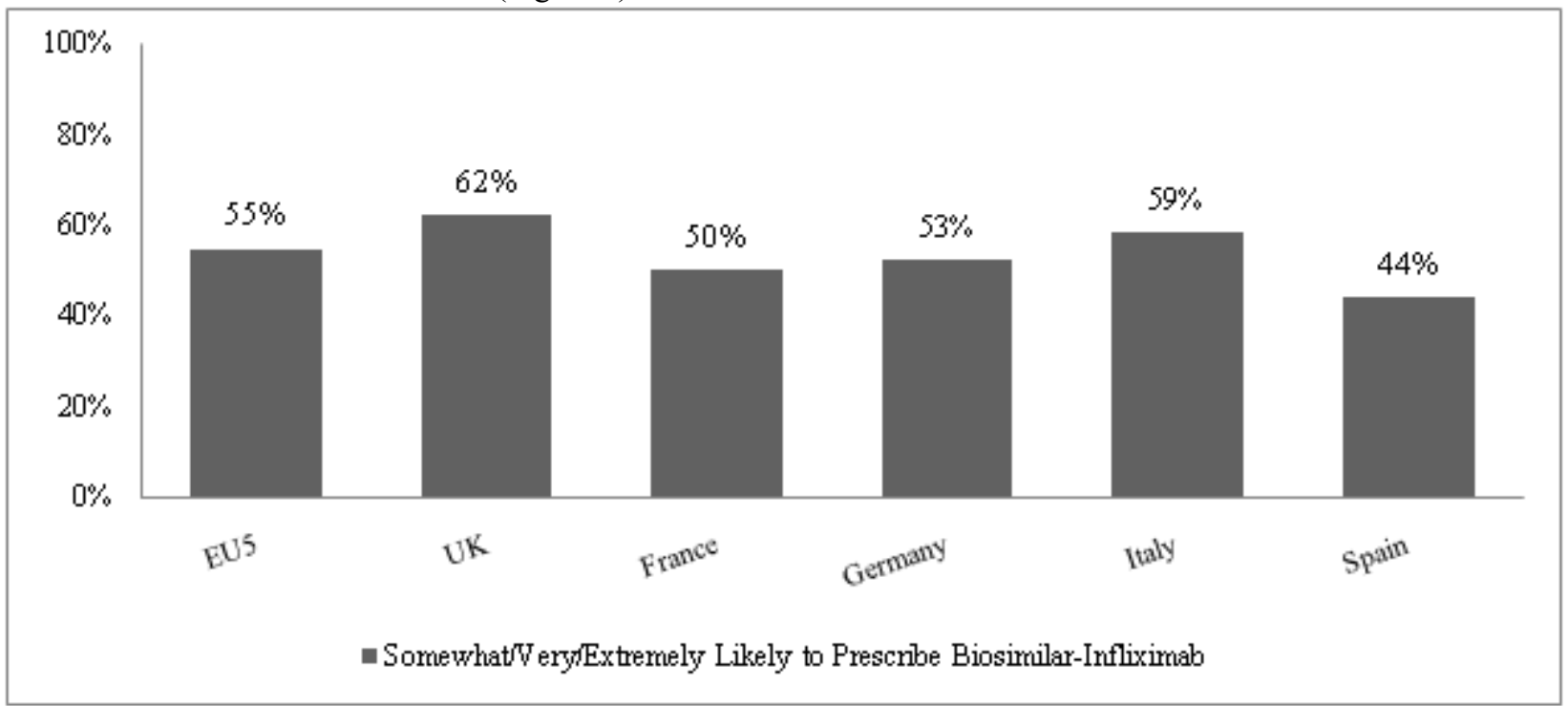

Figure 3: Physician rating of likelihood of prescribing biosimilar infliximab, among biosimilar-infliximab suitable RA patients

Note: EU5: UK, France, Germany, Italy and Spain; UK: United Kingdom.

\section{Discussion}

For an individual RA patient or a physician (Rheumatologist), there might be no direct incentives to switch to a biosimilar Infliximab. However, to establish a sustainable therapeutic management of the immunologic condition that has been traditionally managed by expensive biologics, physicians may need to align with the priorities of the payers (be it, national, regional or local/hospital) and adopt cost-effective approaches to disease management, including the adoption of biosimilars [11,12].In this context, the research finding that for only $55 \%$ of the biosimilarinfliximab suitable patients their physicians expressed the likelihood to prescribe the biosimilar-infliximab eventually assumes importance. This lower likelihood may be driven by the mixed beliefs/perceptions of biosimilar product attributes held $[7,8,12]$.

Past research has suggested that most patients valued treatment recommendations given by their physicians considering their expert knowledge and clinical experience, and the unawareness of having a choice (for alternative treatments) was the main barrier for patient's participation in decision-making[13,14]. This study revealed that physicians reported involving 6 out of 10 patients in treatment decisions; in this scenario, as physicians inform patients about the biosimilar product attributes and its availability, it is likely to influence its uptake.

Clinical evidence is evolving in favor of switching patients from infliximab-biologic to its biosimilar [15-18]. In this context, patients currently on infliximab-biologic could all be considered for biosimilar-infliximab. Physicians in this study identified only a small proportion $(35 \%)$ of patients as biosimilar-infliximab suitable, in the context ofclinical characteristics of patients identified as suitable for biosimilar-infliximab having only marginally severe/worse in comparison to those noted by their physicians as not suitable. Past research had reported the potential influence of physician (rheumatologist) characteristics such as years in practice, on their likelihood to prescribe biosimilars, besides identifying potential barriers to prescribing [8]. Besides these general considerations, exploration of physician reasons for consideration of a specific patient as not suitable for biosimilarand other factors (clinical and non-clinical; patient-centric and physician-centric) influencing physician perceptions and practice behaviors (at individual patientlevel) warrants scrutiny. Although physicians were randomly recruited for this study, the findings represent only the participating physicians, and may vary from those of nonparticipating physicians.

\section{Conclusion}

RA patients considered infliximab-biosimilar not-suitable (per clinical judgment) had been in care for relatively longer period, had relatively lower disease severity and were less involved in treatment decisions, while a slightly larger proportion were on steroids and a smaller proportion on analgesics. Physicians were neither readily prepared to consider biosimilar for all of eligible RA patients nor were they prepared to prescribe the biosimilar to all their patients they considered to be biosimilar-suitable. These research findings may indicate potential barriers to widespread use/adoption of infliximab-biosimilar in the big-5 EU countries. Drivers behind these observed physician perceptions warrant scrutiny, to better generate and communicate evidence that could make physicians comfortable considering switching patients from the infliximab-biologic to its biosimilar, as well as inform clinicians of the best practices to manage RA patients to alleviate disease burden using cost-effective therapeutic options. 


\section{International Journal of Science and Research (IJSR) \\ ISSN (Online): 2319-7064}

Index Copernicus Value (2013): 6.14 | Impact Factor (2015): 6.391

\section{Conflict of Interest}

Authors declare no conflict of interest related to this subject matter.

\section{References}

[1] You S., Cho C-S., Lee I., Hood L., Hwang D., et al. A Systems Approach to Rheumatoid Arthritis, PLoS ONE. 2012; 7(12): e51508.

[2] Zhang W1, Anis AH. The economic burden of rheumatoid arthritis: beyond health care costs. Clin Rheumatol. 2011; 30(1):S25-32.

[3] Lapadula, G., Ferraccioli, G.F. Biosimilars in Rheumatology: Pharmacological and Pharmacoeconomic Issues. Clin. Exp. Rheumatol. 2012;30(69):S102-S106.

[4] Gaffo A., Sagg K.G., Curtis J.R. Treatment of rheumatoid arthritis. American Journal of Health System Pharmacy. 2006; 63(24): 2451-2465

[5] De Keyser, F. Choice of biologic therapy for patients with rheumatoid arthritis: the infection perspective. Current Rheumatology Reviews. 2011; 7(1): 77

[6] Doerner T, Strand V, Castaneda-Hernandez G, Ferraccioli G, Isaacs JD, et al. The role of biosimilars in the treatment of rheumatic diseases. Ann Rheum Dis. 2013;72(3):322-8.

[7] IMS Health. Shaping the Biosimilars Opportunity: A Global Perspective on the Evolving Biosimilars Landscape. 2011. London, UK.

[8] Narayanan S, Nag S. Likelihood of use and perception towards biosimilars in rheumatoid arthritis: A global survey of rheumatologists. Clinical and Experimental Rheumatology. 2016 Jan-Feb;34(1 Suppl 95):S9-11.

[9] Yoo, DH. The Rise of Biosimilars: Potential Benefits and Drawbacks in Rheumatoid Arthritis. Expert Rev. Clin. Immunol.2014;10(8):981-983.

[10]Derbyshire M. Reducing the European healthcare budget with generics and biosimilars. Generics and Biosimilars Initiative Journal. 2014;3(4).

[11] Aapro MS. What do prescribers think of biosimilars? Targ Oncol. 2012;7 (1):S51-5.

[12] Kurki P. Biosimilars for prescribers. Generics and Biosimilars Initiative Journal (GaBI Journal). 2015;4(1):33-5.

[13] Dilla T, Rentero ML, Comellas M, Lizan L, Sacristán JA. Patients' Preferences For Rheumatoid Arthritis Treatments And Their Participation In The Treatment Decision-Making Process. A Systematic Review Of Literature. Value in Health. 2015; 18(7):A652.

[14] Mathews AL, Coleska A, Burns PB, Chung KC. The Evolution of Patient Decision-Making Regarding Medical Treatment of Rheumatoid Arthritis. Arthritis Care Res (Hoboken). 2015 Aug 28.

[15] Yoo DH, Racewicz A, Brzezicki J, Yatsyshyn R, Arteaga ET, et al. A phase III randomized study to evaluate the efficacy and safety of CT-P13 compared with reference infliximab in patients with active rheumatoid arthritis: 54-week results from the PLANETRA study. Arthritis Res Ther. 2016;18(1):82.

[16] Canadian Agency for Drugs and Technologies in Health $(\mathrm{CADTH})$. Switching from Innovator to Biosimilar (Subsequent Entry) Infliximab: A Review of the
Clinical Effectiveness, Cost-Effectiveness, and Guidelines [Internet]. CADTH Rapid Response Reports. 2015 Feb 26. Available at: http://www.ncbi.nlm.nih.gov/pubmedhealth/PMH00858 14/pdf/PubMedHealth_PMH0085814.pdf.

[17] Taylor P. A scientific update on biosimilar infliximab (CT-P13) in rheumatic diseases. Expert Rev Clin Immunol. 2015; 11(1): S1-4.

[18] Nikiphorou E, Kautiainen H, Hannonen P, Asikainen J, Kokko A et al.Clinical effectiveness of CT-P13 (Infliximab biosimilar) used as a switch from Remicade (infliximab) in patients with established rheumatic disease. Report of clinical experience based on prospective observational data. Expert Opin Biol Ther. 2015; 15(12): 1677-83.

\section{Author Profile}

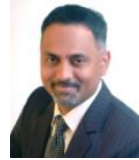

Siva Narayanan is an executive with two decades of experience in developing product value propositions through market/customer focus, research excellence, and brand strategy support.Siva built a strong career in HEOR and Market Access arena within Pharmaceutical industry through tenures at Human Genome Sciences (GSK), Merck \& Co., Boehringer-Ingelheim and BMS covering several therapeutic areas and markets. Within healthcare provider sector, Siva has in-depth experience in Long Term Care (LTC) segment, through his tenure at Beverly Enterprises covering the clinical and strategic evaluations across a spectrum of LTC services.In the consulting arena, Siva held a position of Senior Vice President leading Global Treatment Performance Optimization, HEOR Business Unit at TNS (now, part of Kantar), and as Senior Vice President and Global Head at Ipsos, leading the Global Evidence, Value and Access division to help clients generate and communicate evidence to support their product value propositions. 